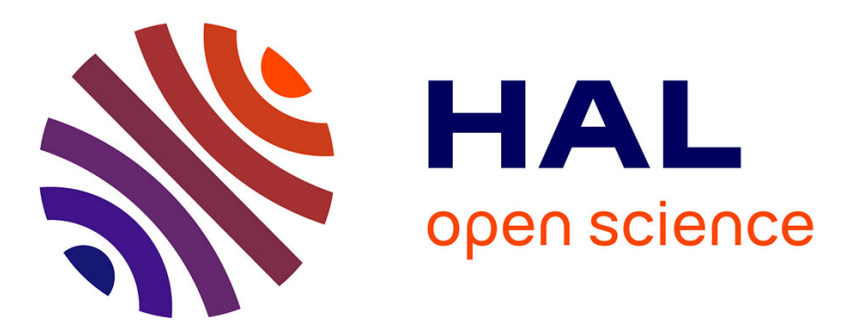

\title{
Biobased Amphiphilic Block Copolymers by RAFT-mediated PISA in Green Solvent
}

Fanny Coumes, Mauricio Balarezo, Jutta Rieger, François Stoffelbach

\section{To cite this version:}

Fanny Coumes, Mauricio Balarezo, Jutta Rieger, François Stoffelbach. Biobased Amphiphilic Block Copolymers by RAFT-mediated PISA in Green Solvent. Macromolecular Rapid Communications, 2020, 41 (9), pp.2000002. 10.1002/marc.202000002 . hal-02992128

\section{HAL Id: hal-02992128 \\ https://hal.science/hal-02992128}

Submitted on 6 Nov 2020

HAL is a multi-disciplinary open access archive for the deposit and dissemination of scientific research documents, whether they are published or not. The documents may come from teaching and research institutions in France or abroad, or from public or private research centers.
L'archive ouverte pluridisciplinaire HAL, est destinée au dépôt et à la diffusion de documents scientifiques de niveau recherche, publiés ou non, émanant des établissements d'enseignement et de recherche français ou étrangers, des laboratoires publics ou privés. 


\title{
Communication
}

\section{Biobased Amphiphilic Block Copolymers by RAFT-mediated PISA in Green Solvent}

Fanny Coumes*, Mauricio Balarezo, Jutta Rieger, François Stoffelbach*

Sorbonne Université, CNRS Institut Parisien de Chimie Moléculaire. UMR 8232, Equipe

Chimie des Polymères 75252 Paris Cedex 05 (France)

E-mail: francois.stoffelbach@ sorbonne-universite.fr, fanny.coumes@ sorbonne-universite.fr

Keywords: PISA, RAFT dispersion polymerization, biobased monomer, amphiphilic copolymer

\begin{abstract}
Biobased amphiphilic diblock copolymers are prepared thanks to the combination of reversible addition-fragmentation transfer (RAFT) polymerization and polymerizationinduced self-assembly (PISA) in an ecofriendly solvent mixture. Firstly, the formation of a poly(acrylic acid) macroRAFT agent (PAA-TTC) is performed in water at $70{ }^{\circ} \mathrm{C}$. Then, in a series of experiments, the PAA-TTC macroRAFT agent is used directly, without purification, as both chain transfer agent and stabilizing agent in the RAFT-PISA of menthyl acrylate $(\mathrm{MnA})$ in dispersion in an ethanol/water mixture. The polymerizations of MnA are fast with high final conversions and well-controlled amphiphilic diblock copolymers are synthesized. Stable, submicrometric spherical particles composed of the diblock copolymers are formed. The influence of the monomer concentration and the length of the solvophobic block on the diameter of the self-assemblies is studied by means of dynamic light scattering and cryotransmission electron-microscopy.
\end{abstract}




\section{WILEY-VCH}

\section{Introduction}

Thanks to the combination of reversible-deactivation radical polymerization (RDRP) techniques $^{[1]}$ and polymerization-induced self-assembly (PISA) ${ }^{[2-5]}$, it is nowadays possible to produce amphiphilic block copolymer assemblies in a straightforward way, in a large variety of solvents such as alcohols or water. This approach can be considered as a green process, as it proceeds with a minimum of compounds using environmentally safe solvents, producing the targeted copolymers in high solids contents (typically up to $40 \mathrm{wt} \%$ ) and with high yields. However, until now all amphiphilic block copolymers synthesized by such processes were produced from petroleum-based monomers. There is thus a need to perform investigations in order to use biobased monomers from renewable resources as an alternative solution. Hitherto, only very few examples of RDRP of biobased monomers in heterogeneous conditions have been reported. For example, Caillol et al. have managed to synthesize biobased latexes by free radical emulsion polymerization stabilized by surfactants and/or RDRP using acrylates and methacrylates derived from biobased molecules such as vanillin ${ }^{[6]}$, eugenol ${ }^{[7-9]}$ and/or cardanol $^{[10-12]}$ Asua et al. have also recently reported the synthesis of biobased triblock copolymers using reversible addition-fragmentation chain transfer $(\mathrm{RAFT})^{[13-15]}$ (co)polymerization either in homogeneous ${ }^{[16]}$ or heterogeneous conditions, using conventional surfactants as stabilizers. ${ }^{[17,18]}$ Nevertheless, all these synthetic approaches require the addition of free molecular surfactants to stabilize the particles produced in a heterogeneous polymerization process. Looking at hydrophilic biobased monomers, it is nowadays well known that acrylic acid can be synthesized from renewable sources. Indeed, lactic acid, which can be produced from the biomass by chemical reaction or fermentation methods ${ }^{[19]}$, can provide acrylic acid (AA) $)^{[20]}$ by dehydration. This synthesis pathway is nowadays considered as an alternate process to the petrochemical process (obtained by oxidation of propene). Finally, several acrylic monomers can be prepared from AA by esterification of bio-sourced 


\section{WILEY-VCH}

alcohols. Herein, with the objective of producing diblock copolymers derived from the biomass instead of fossil resources by PISA, we decided to use the RAFT polymerization technique $^{[13-15]}$ due to its tolerance to a broad range of reaction conditions and monomer families. In that respect, a hydrophilic macromolecular chain transfer agent (macroRAFT) based on poly(acrylic acid) was chain extended with a second, less soluble monomer derived from menthol (naturally present in peppermint, for instance). In an ecofriendly solvent (here a mixture of ethanol and water was chosen) the polymerization proceeds under dispersion polymerization conditions to form an amphiphilic diblock copolymer that self-assembles in the course of the polymerization (Scheme 1). While the synthesis of poly(L-menthyl acrylate) and double hydrophobic poly(L-menthyl acrylate)-block-poly(methyl acrylate) diblock copolymers has already been reported using single electron transfer living radical polymerization (SET-LRP) in a series of alcohols ${ }^{[21]}$ and atom transfer radical polymerization $(\mathrm{ATRP})^{[22]}$ respectively, to the best of our knowledge there is no example reporting the synthesis of amphiphilic menthyl acrylate based block copolymer, nor any example of entirely biobased amphiphilic copolymers in general obtained by a PISA process. As mentioned above, RAFT-mediated PISA in heterogeneous polymerization conditions was exclusively achieved in the presence of a hydrophobic petroleum-based monomer. In this communication, we describe for the first time a RAFT-mediated PISA using only bio-sourced monomers. 


\section{WILEY-VCH}

\section{Results and Discussion}

Menthyl acrylate (MnA) was synthesized by esterification of D,L-menthol with acryloyl chloride in the presence of triethylamine following a reported procedure. ${ }^{[23]}$ The monomer was obtained as a transparent liquid and the ${ }^{1} \mathrm{H}$ NMR spectrum of $\mathrm{MnA}$ recorded in $\mathrm{CDCl}_{3}$ displays the characteristic signals of the monomer's vinyl and cyclohexyl groups (Figure S1). Before using the monomer in the PISA process proceeding in heterogeneous conditions, we firstly investigated its ability to be radically homopolymerized in a controlled fashion by RAFT solution polymerization using a carboxylic acid functional trithiocarbonate-type RAFT agent (HOOC-TTC) ${ }^{[24]}$ (Scheme 1) well-known to control the polymerization of acrylates and acrylamides. After 6 hours of reaction in anisole at $70{ }^{\circ} \mathrm{C}$, in the presence of 2,2'-azobis(2methylproprionitrile) (AIBN) as an initiator, the polymer was recovered by precipitation and analyzed by size exclusion chromatography (SEC). As shown in Figure S2, the RAFT homopolymerization was controlled as the polymer displayed a dispersity $\left(\bigoplus=M_{w} / M_{n}\right)$ below 1.25 and a number-average molar mass determined by ${ }^{1} \mathrm{H}$ NMR, $M_{\mathrm{n}, \mathrm{NMR}}\left(41.0 \mathrm{~kg} \cdot \mathrm{mol}^{-1}\right)$ in good agreement with the theoretical value $\left(41.8 \mathrm{~kg} \mathrm{~mol}^{-1}\right)$ indicating that the number of chains was governed by the RAFT agent concentration. The efficiency of the transfer reaction was also confirmed by using SEC equipped with an in-line UV detector. Indeed, SEC chromatogram obtained with the UV detector at $309 \mathrm{~nm}$ shows the presence of the trithiocarbonate functionality which strongly absorbs at this wavelength. ${ }^{[25]}$ The UV signal overlays with the RI signal, which indicates that the whole chains distribution presents the trithiocarbonate moiety. Discrepancy between SEC molar masses and theoretical one could be observed due to the use of a conventional PS calibration. In order to get more accurate values, we decided to determine the absolute $M_{\mathrm{n}}$ of this homopolymer (PMnA) by using a SEC equipped with an in-line static light scattering (SLS) detector. Using the in-line RI detector of the SEC apparatus, as described previously, ${ }^{[26]}$ a refractive index increment $(d n / d C)$ of 0.085 


\section{WILEY-VCH}

$\mathrm{mL} \cdot \mathrm{g}^{-1}$ was determined in THF, providing a $M_{\mathrm{n}, \mathrm{LS}}$ of $37.9 \mathrm{~kg} \cdot \mathrm{mol}^{-1}$ in better correlation with theoretical value $\left(41.8 \mathrm{~kg} \cdot \mathrm{mol}^{-1}\right)$. Thermal analysis by differential scanning calorimetry and thermogravimetry were performed on the homopolymer showing respectively a glass transition temperature of $56{ }^{\circ} \mathrm{C}$ and a thermal degradation at about $300{ }^{\circ} \mathrm{C}$ (Figure S3), in accordance with data found in the literature. ${ }^{[21,22]}$ Then, we evaluated the possibility to synthesize amphiphilic diblock copolymers possessing a hydrophilic block based on poly(acrylic acid) and a poly(menthyl acrylate) hydrophobic block using the PISA technique under dispersion polymerization conditions (in conditions where menthyl acrylate is soluble, and poly(menthyl acrylate) is not). To this end, in a first step, we performed a kinetic study on the RAFT polymerization of acrylic acid in water at $70{ }^{\circ} \mathrm{C}$, initiated by $4,4^{\prime}$-azobis(4cyanovaleric acid) (ACPA), in presence of HOOC-TTC as chain transfer agent in order to reach high conversions while maintaining a good polymerization control. As depicted in Figure S4, the polymerization under these conditions proceeded rapidly exhibiting pseudofirst order kinetics with no induction period. A high monomer conversion ( 92\%) was reached within only $1 \mathrm{~h} 30$. Moreover, the RAFT polymerization of acrylic acid (AA) was controlled as the growing polymer exhibited a linear increase of $M_{\mathrm{n}}$ with monomer conversion and a $Ð$ below 1.1 . Throughout the polymerization, SEC traces were essentially symmetrical and narrow in shape (Figure S4b). Then, PAA macroRAFTs were synthesized in water by targeting conversions higher than $95 \%$ and directly utilized - without any purification steps as reactive stabilizer in the dispersion polymerization of $\mathrm{D}, \mathrm{L}-\mathrm{menthyl}$ acrylate, conducted at $50{ }^{\circ} \mathrm{C}$ in a mixture of ethanol and water (80/20 in weight), in which the monomer is fully soluble, using 2,2'-azobis[2-(2-imidazolin-2-yl)propane]dihydrochloride (VA-044) as a thermal initiator. A series of polymerizations was performed, at a fixed monomer concentration $(\sim 10 \mathrm{wt} \%)$, varying the degree of polymerization (DP) of the hydrophobic block (DP ranging from 50 to 300), see Table 1, experiments 1 to 4 . As shown in Table 1 and in Figure 1a, all RAFT polymerizations reached a high monomer conversion (generally $\geq$ 


\section{WILEY-VCH}

91\%) within 2 hours of reaction. The size exclusion chromatograms of the final block copolymers were narrow with a dispersity generally below 1.7 (Figure 1b and Figure S5), showing a slight tailing toward the lower molar mass side. Moreover, SEC traces showed a complete shift of the macroRAFT agent signal to higher molar masses, attesting the good blocking efficiency of the polymerizations. One may notice in Table 1, that the experimental molar masses differ significantly from the theoretical values. Such differences can be explained by the use of a conventional PS calibration which is not representative of the copolymer formed. With increasing DP of the hydrophobic block, the appearance of the solutions changed slightly towards more opaque dispersions, which remained colloidally stable. Such dispersions were diluted at $1 \mathrm{wt} \%$ in ethanol/water (80/20 in weight) and studied by dynamic light scattering (DLS) to determine the particle diameters. As reported in Table 1, by increasing the chain length of the hydrophobic block (DP ranging from 50 to 300), the particle diameter of the final dispersions increased from 30 to $60 \mathrm{~nm}$. Thereby the particle diameter can be tuned by simply adjusting the targeted DP of the PMnA core-forming block as previously reported for spherical nanoparticles prepared via RAFT-PISA. ${ }^{[27-32]}$

In addition, cryo-TEM analysis was also performed on the dispersion solution obtained in experiment 4 diluted at $1 \mathrm{wt} \%$ in the same mixture of solvents. While a monodisperse distribution $\left(\sigma<0.1\right.$ denoting a monodisperse sample) with an average diameter, $D_{\mathrm{z}}$, of $59 \mathrm{~nm}$ was obtained by DLS (Figure 2a), a smaller diameter $\left(D_{\mathrm{n}} \sim 40 \mathrm{~nm}\right)$ along with particles spherical in shape was observed by cryo-TEM (Figure 2b). Such discrepancy is not unexpected considering that DLS gives a hydrodynamic diameter, while the hydrated PAA block is supposedly not visible in cryo-TEM (due to a lack of contrast).

In order to develop an even greener process by reaching higher final solids contents, we performed two other series of experiments at higher monomer concentration (at $\sim 15$ and 25 wt\%, see Table 1, experiments 5 to 10). As depicted in Figure S6, these extensions exhibited similar polymerization behavior, yielding similar experimental molar masses when the same 


\section{WILEY-VCH}

DP was targeted (for example in the experiments 3, 6 and 9 for a targeted DP $=150$ ) and maintaining a high monomer conversion. Again, a significant discrepancy between theoretical and experimental molar masses determined by SEC was observed. Using the same approach as previously, we decided to determine the absolute $M_{\mathrm{n}}$ values for representative copolymers by using a SEC equipped with an in-line SLS detector. After quantitative methylation of the carboxylic acid groups yielding PMeA- $b$-PMnA copolymers, their $d n / d C$ was determined providing $M_{\mathrm{n}, \mathrm{LS}}$ values that were in good agreement with the theoretically ones (Table S1), confirming a good control over the polymerization. The amount of non-reacted PAA in the final copolymers exhibiting the highest dispersities (DP of 300, experiments 4, 7 and 10 in Table 1) was quantified (see details in SI). For all samples, the copolymers contain less than 5 wt $\%$ of PAA (3.4, 0.3 and $4.7 \mathrm{wt} \%$ for experiments 4,7 and 10 respectively).

The particle diameter of the polymerizations performed at 15 and $25 \mathrm{wt} \%$ was also determined by DLS (see Table 1). An increase in particle diameter with DP was again observed, and overall no significant impact of the initial monomer concentration $(10,15$ or 25 wt\%) was observed, as previously reported by Quémener et al. ${ }^{[33]}$, revealing the robustness and colloidal stability of the process with regard to variations in monomer concentration at which the polymerization was performed. Cryo-TEM analyses (see Figure 2d and $2 \mathbf{f}$ for experiment 7 and experiment 10 respectively) showed spherical particles that were quite homogeneous in size, and no aggregates were detected. Once again, the diameters observed for both experiments $7\left(D_{\mathrm{n}}=30 \mathrm{~nm}\right)$ and $10\left(D_{\mathrm{n}}=43 \mathrm{~nm}\right)$ were slightly lower than those determined by DLS (Figure 2c and 2e, Table 1). On the other hand, while spherical particles of similar diameters were obtained at 10,15 and 25 wt $\%$, macroscopically a significant increase in viscosity until gel formation was observed for all extensions performed at $25 \mathrm{wt} \%$. In view of the spherical morphology, we assume that this gel-like aspect of the dispersions is caused by a jamming effect. In order to know if a switching of solvent has an impact on the nanoparticle morphologies, we also tried to perform DLS and cryo-TEM analyses in water but 


\section{WILEY-VCH}

the dispersions were unstable in pure water, without $\mathrm{pH}$ adjustment. However, in slightly basic conditions $(\mathrm{pH}=8.4)$ the dispersions remained stable and no significant change in particle morphology was observed (see for example cryo-TEM Figure S8). For all former syntheses, the racemic mixture, D,L-menthyl acrylate, was used. In order to know if the use of an enantiopure monomer could affect the self-assembly of the copolymer in PISA, we synthesized the enantiopure L-menthyl acrylate from L-menthol and polymerized it in PISA conditions comparable to experiment 10 (see Table 1 experiment 10bis). Quasi no influence on the polymerization was noticed, and the analysis of the particles by DLS and cryo-TEM revealed no significant difference in size or in shape (Figure S7). The use of enantiopure Lmenthyl acrylate did thus not influence the self-assembly of the copolymer, at least in the current experimental conditions.

\section{Conclusions}

In conclusion, a series of biobased amphiphilic block copolymer with various degrees of polymerization for the hydrophobic block was prepared by RAFT-mediated PISA in green solvent reaching solid contents up to $25 \mathrm{wt} \%$ and quasi quantitative monomer conversion. A considerable advantage of this PISA process relies on the one-pot/two-step process, which means that all steps can be conducted successively in the same vessel. Stable, submicrometric particles composed of self-assembled amphiphilic diblock copolymer chains were formed. No influence of the monomer concentration (from 10 to $25 \mathrm{wt} \%$ ) or the length of the solvophobic block (DP between 50 to 300) on the morphology of the self-assemblies was observed, only spherical nanoparticles were formed which diameter increased from 30 to $60 \mathrm{~nm}$ with increasing DP of PMnA. The developed process paves the way for the formation of a new class of biobased copolymers for new applications. Our current work is directed towards the 


\section{WILEY-VCH}

use of other biobased monomers and their polymerization by a PISA approach in aqueous emulsion.

\section{Supporting Information}

Supporting Information is available from the Wiley Online Library or from the author.

Materials, general polymerization procedure of PAA-TTC, chain extension polymerization, characterizations, Table S1, and Figures S1-S7.

\section{Acknowledgements}

We thank Jean-Michel Guigner for the cryo-TEM measurements.

Received: ((will be filled in by the editorial staff))

Revised: ((will be filled in by the editorial staff))

Published online: ((will be filled in by the editorial staff))

\section{References}

[1] Shanmugam, S. \& K. Matyjaszewski. in Reversible Deactivation Radical Polymerization: Mechanisms and Synthetic Methodologies ACS Symposium Series (American Chemical Society, 2018). vol. 1284 1-39

[2] Charleux, B., G. Delaittre, J. Rieger \& F. D’Agosto. Macromolecules 2012, 45, 67536765

[3] Warren, N. J. \& S. P. Armes. J. Am. Chem. Soc. 2014, 136, 10174-10185

[4] Wang, X., L. Shen \& Z. An. Prog. Polym. Sci. 2018, 83, 1-27

[5] Lansalot, M. \& J. Rieger. Macromol. Rapid Commun. 2019, 40, 1-3

[6] Fache, M., B. Boutevin \& S. Caillol. Eur. Polym. J. 2015, 68, 488-502

[7] Molina-Gutiérrez, S., A. Manseri, V. Ladmiral, R. Bongiovanni, S. Caillol \& P. 


\section{WILEY-VCH}

Lacroix-Desmazes. Macromol. Chem. Phys. 2019, 1900179, 1-10

[8] Molina-Gutiérrez, S., V. Ladmiral, R. Bongiovanni, S. Caillol \& P. Lacroix-Desmazes. Ind. Eng. Chem. Res. 2019, 58, 21155-21164

[9] Fei, M., T. Liu, T. Fu, J. Zhang, Y. Wu, R. Qiu \& W. Liu. ACS Sustain. Chem. Eng. 2019, 7, 17808-17816

[10] Ladmiral, V., R. Jeannin, K. Fernandes Lizarazu, J. Lai-Kee-Him, P. Bron, P. LacroixDesmazes \& S. Caillol. Eur. Polym. J. 2017, 93, 785-794

[11] Li, W. S. J., C. Negrell, V. Ladmiral, J. Lai-Kee-Him, P. Bron, P. Lacroix-Desmazes, C. Joly-Duhamel \& S. Caillol. Polym. Chem. 2018, 9, 2468-2477

[12] Caillol, S. Curr. Opin. Green Sustain. Chem. 2018, 14, 26-32

[13] Barner-kowollik, C. (Wiley-VCH, 2008).

[14] Barner-Kowollik, C. \& S. Perrier. J. Polym. Sci. part A Polym. Chem. 2008, 46, $5715-5723$

[15] Chiefari, J., Y. K. Chong, F. Ercole, J. Krstina, J. Jeffery, T. P. T. Le, R. T. A. Mayadunne, G. F. Meijs, C. L. Moad, G. Moad, E. Rizzardo \& S. H. Thang. Macromolecules 1998, 31, 5559-5562

[16] Noppalit, S., A. Simula, N. Ballard, X. Callies, J. M. Asua \& L. Billon. Biomacromolecules 2019, 20, 2241-2251

[17] Noppalit, S., A. Simula, L. Billon \& J. M. Asua. Polym. Chem. 2020, DOI: 10.1039/C9PY01667H doi:10.4324/9781315079097-35

[18] Noppalit, S., A. Simula, L. Billon \& J. M. Asua. ACS Sustain. Chem. Eng. 2019, 7, 17990-17998

[19] Boontawan, P., S. Kanchanathawee \& A. Boontawan. Biochem. Eng. J. 2011, 54, 192199

[20] Yan, B., L.-Z. Tao, Y. Liang \& B.-Q. Xu. ACS Catal. 2014, 4, 1931-1943

[21] Bensabeh, N., J. C. Ronda, M. Galia, V. Cadiz \& G. Lligadas. Biomacromolecules 


\section{WILEY-VCH}

2018, 19, 1256-1268

[22] Liu, S. \& M. K. Mishra. Macromolecules 2007, 40, 867-871

[23] Baek, S. S. \& S. H. Hwang. Polym. Bull. 2016, 73, 687-701

[24] Kujawa, P., F. Segui, S. Shaban, C. Diab, Y. Okada, F. Tanaka \& F. M. Winnik. Macromolecules 2006, 39, 341-348

[25] Zhang, W., F. D’Agosto, P.-Y. Y. Dugas, J. Rieger \& B. Charleux. Polymer 2013, 54, 2011-2019

[26] Velasquez, E., G. Pembouong, J. Rieger, F. Stoffelbach, O. Boyron, B. Charleux, F. D’Agosto, M. Lansalot, P. E. Dufils \& J. Vinas. Macromolecules 2013, 46, 664-673

[27] Li, Y. \& S. P. Armes. Angew. Chemie Int. Ed. 2010, 49, 4042-4046

[28] Blanazs, A., A. J. Ryan \& S. P. Armes. Macromolecules 2012, 45, 5099-5107

[29] Fielding, L. A., M. J. Derry, V. Ladmiral, J. Rosselgong, A. M. Rodrigues, L. P. D. Ratcliffe, S. Sugihara \& S. P. Armes. Chem. Sci. 2013, 4, 2081-2087

[30] Jones, E. R., O. O. Mykhaylyk, M. Semsarilar, M. Boerakker, P. Wyman \& S. P. Armes. Macromolecules 2016, 49, 172-181

[31] Zhang, W., F. D’Agosto, O. Boyron, J. Rieger, B. Charleux, F. D’Agosto, O. Boyron, J. Rieger, B. Charleux, F. D’Agosto, O. Boyron, J. Rieger \& B. Charleux. Macromolecules 2011, 44, 7584-7593

[32] Rieger, J., F. Stoffelbach, C. Bui, D. Alaimo, C. Jérôme, B. Charleux, F. Stoffelbach, C. Bui \& J. Rieger. Macromolecules 2008, 41, 4065-4068

[33] Upadhyaya, L., M. Semsarilar, R. Fernández-Pacheco, G. Martinez, R. Mallada, A. Deratani \& D. Quemener. Polym. Chem. 2016, 7, 1899-1906 


\section{WILEY-VCH}

Scheme 1. Reaction scheme for the synthesis of the PAA macroRAFT agent and its subsequent chain extension with MnA to produce of PAA- $b$-PMnA block copolymers via RAFT-mediated dispersion polymerization

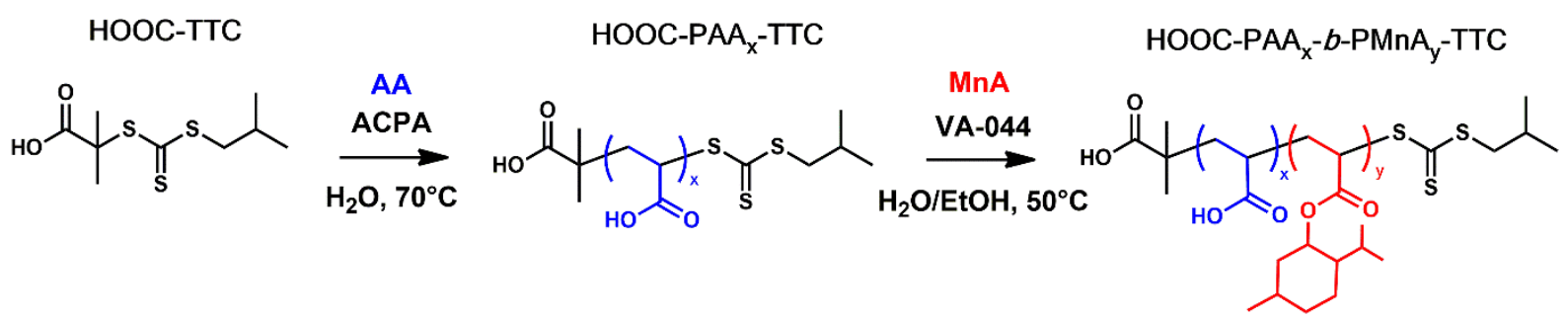




\section{WILEY-VCH}

Figure 1. (a) Kinetic monitoring of the dispersion polymerization of menthyl acrylate conducted in a mixture of ethanol and water (80/20 in weight) at $50{ }^{\circ} \mathrm{C}$ using 2,2 -azobis[2-(2imidazolin-2-yl)propane]dihydrochloride (VA-044) as thermal initiator and in the presence of PAA-TTC at $~ 10 \mathrm{wt} \%$ monomer concentration targeting different DP of the second block (DP $=50,100,150,300)$ (b) Evolution of the size exclusion chromatograms for the different targeted DP.

(a)

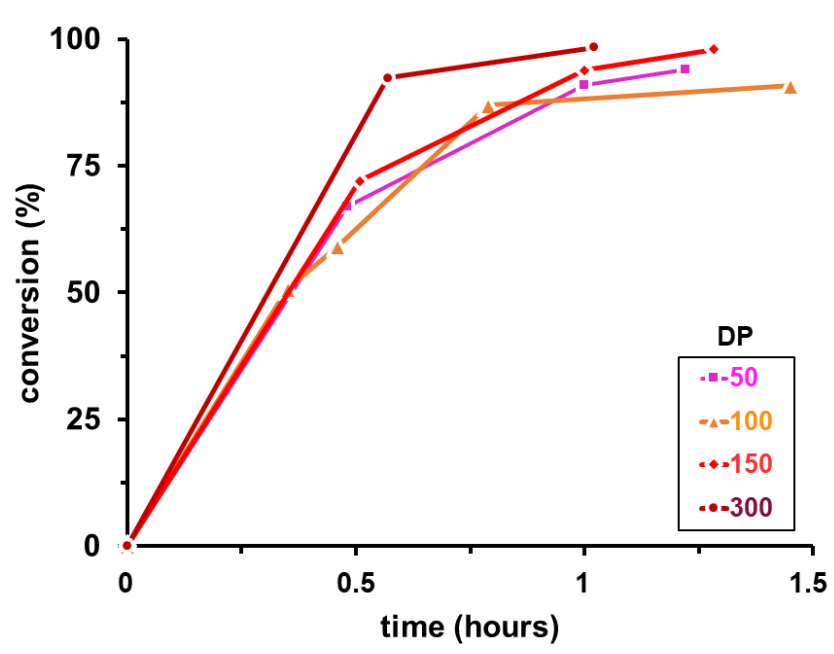

(b)

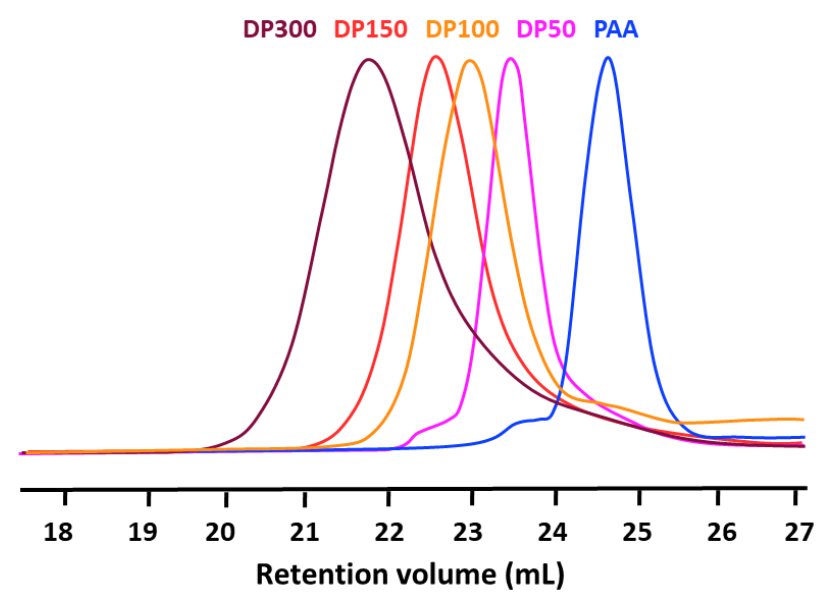




\section{WILEY-VCH}

Figure 2. Final size distributions determined by DLS at $25{ }^{\circ} \mathrm{C}$ and representative cryo-TEM images for the dispersions obtained with the same targeted DP of the PMnA block $(\mathrm{DP}=300)$ at different solids content in experiment $4(\mathrm{a}+\mathrm{b})\left([\mathrm{MnA}]_{0}=10 \mathrm{wt} \%\right)$, experiment $7(\mathrm{c}+\mathrm{d})$ $\left([\mathrm{MnA}]_{0}=15 \mathrm{wt} \%\right)$ and experiment $10(\mathrm{e}+\mathrm{f})\left([\mathrm{MnA}]_{0}=25 \mathrm{wt} \%\right)($ Table 1) recorded at a concentration of $1 \mathrm{wt} \%$ in a mixture of ethanol and water (80/20 in weight).

(a)



(c)

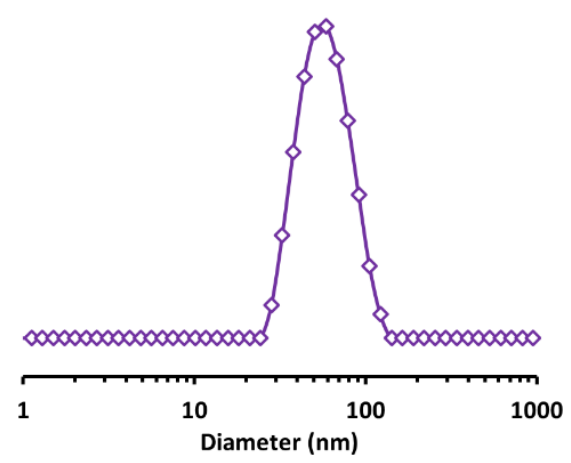

(e)



(b)

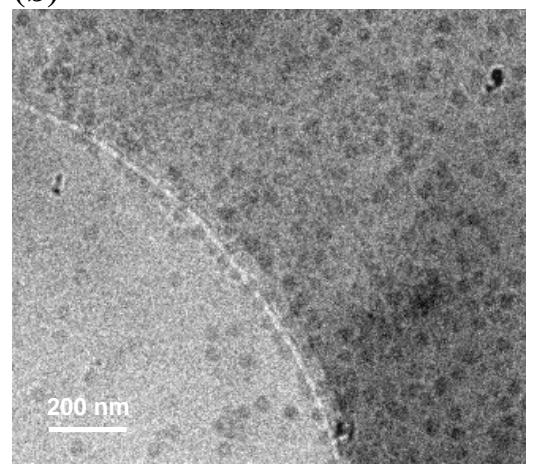

(d)



(f)

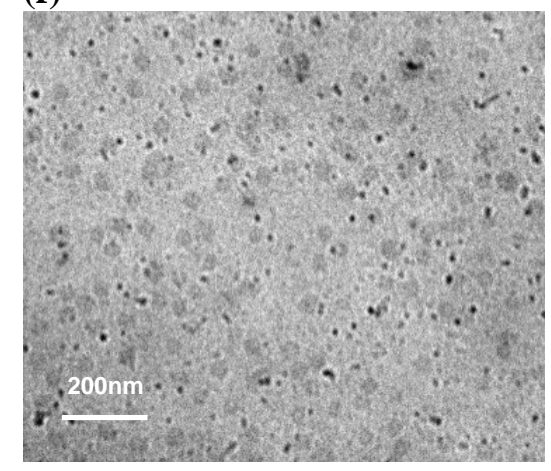


Table 1. Macromolecular and colloidal characteristics of the polymer latexes prepared by dispersion polymerization of D,L-menthyl acrylate (MnA) in the presence of PAA-TTC as a macromolecular RAFT agent

\begin{tabular}{|c|c|c|c|c|c|c|c|c|c|c|}
\hline Entry & $\begin{array}{c}\text { wt \% of } \\
\text { Mn } A_{0} \\
\text { in latex }\end{array}$ & $\begin{array}{c}M_{\mathrm{n}, \mathrm{PAA}-\mathrm{TTC}} \\
\left(\mathrm{kg}^{-1} \mathrm{~mol}^{-1}\right)\end{array}$ & $\begin{array}{c}{[\mathrm{MnA}]_{0} /} \\
{[\mathrm{TTC}]_{0}}\end{array}$ & $\begin{array}{c}{[\mathrm{MnA}]_{0}} \\
(\mathrm{M})\end{array}$ & $\begin{array}{l}\text { Time } \\
\text { (min) }\end{array}$ & $\begin{array}{l}\text { Conv } \\
(\%)^{a)}\end{array}$ & $\begin{array}{c}M_{\mathrm{n}, \mathrm{th}} \\
\left.\left(\mathrm{kg}^{-1} \mathrm{~mol}^{-1}\right)^{\mathrm{b}}\right)\end{array}$ & $\begin{array}{c}M_{\mathrm{n}, \mathrm{SEC}} \\
\left(\mathrm{kg} \mathrm{mol}^{-1}\right)^{\mathrm{c})}\end{array}$ & $\theta^{c}$ & $D_{z}(\mathrm{~nm}) ;(\sigma)^{\mathrm{d})}$ \\
\hline 1 & 9.9 & 3.8 & 50 & 0.47 & 72 & 94 & 13.5 & 8.9 & 1.25 & $28(0.08)$ \\
\hline 2 & 10 & 3.8 & 100 & 0.44 & 83 & 91 & 22.7 & 14.6 & 1.25 & $37(0.19)$ \\
\hline 3 & 10.5 & 3.8 & 150 & 0.46 & 77 & 98 & 36.6 & 16.1 & 1.63 & $44(0.13)$ \\
\hline 4 & 10.4 & 3.8 & 300 & 0.46 & 62 & 98 & 64.8 & 20.9 & 1.78 & $59(0.04)$ \\
\hline 5 & 14.1 & 3.8 & 100 & 0.67 & 60 & 96 & 23.3 & 14.9 & 1.28 & $33(0.06)$ \\
\hline 6 & 14.9 & 3.9 & 150 & 0.70 & 120 & 99 & 35.9 & 16.9 & 1.44 & $39(0.10)$ \\
\hline 7 & 15.2 & 3.9 & 300 & 0.71 & 120 & 97 & 64.9 & 27.2 & 1.63 & $54(0.11)$ \\
\hline 8 & 23.5 & 3.8 & 100 & 1.27 & 90 & 95 & 23.7 & 14.7 & 1.21 & $39(0.11)$ \\
\hline 9 & 25.1 & 3.8 & 150 & 1.37 & 105 & 96 & 33.6 & 16.1 & 1.49 & $43(0.06)$ \\
\hline 10 & 25.0 & 3.8 & 300 & 1.33 & 120 & 99 & 65.8 & 27.6 & 1.50 & $59(0.09)$ \\
\hline $10 \mathrm{bis}^{\mathrm{e})}$ & 24.7 & 3.8 & 300 & 1.35 & 107 & 92 & 62.8 & 27.3 & 1.43 & $59(0.06)$ \\
\hline
\end{tabular}

All polymerizations were carried out at $50{ }^{\circ} \mathrm{C}$, in a water/ethanol mixture (20/80 in weight) using VA-044 as an initiator with an initial molar ratio, $\mathrm{n}_{\mathrm{PAA} \text { macroRAFT, } 0} / \mathrm{n}_{\mathrm{VA}-044,0}=2$. ${ }^{a)}$ Monomer conversion was determined by ${ }^{1} \mathrm{H}$ NMR. ${ }^{\text {b) }}$ Theoretical number-average molar mass at the experimentally determined conversion. ${ }^{c}$ Number-average molar mass $\left(M_{\mathrm{n}}\right)$ and dispersity $\left(M_{\mathrm{w}} / M_{\mathrm{n}}\right)$ determined by SEC for the methylated copolymers using a polystyrene calibration and recalculated for the nonmethylated ones. ${ }^{\mathrm{d})} D_{\mathrm{z}}$ is the z-average particle diameter from dynamic light scattering analysis, performed at $1 \mathrm{wt} \%$ in the ethanol/water mixture (the lower the polydispersity factor, $\sigma$, the narrower the particle size distribution). e) The polymerization was performed with L-menthyl acrylate. 


\section{WILEY-VCH}

\section{Text for TOC}

Biobased amphiphilic block copolymer with various degrees of polymerization for the hydrophobic block is prepared by RAFT-mediated PISA in green solvent. Stable, submicrometric spherical particles are formed.

Keyword : Biobased amphiphilic copolymers

Fanny Coumes*, Mauricio Balarezo, Jutta Rieger, François Stoffelbach*

Biobased Amphiphilic Block Copolymers by RAFT-mediated PISA in Green Solvent

\section{FIGURE FOR TOC}

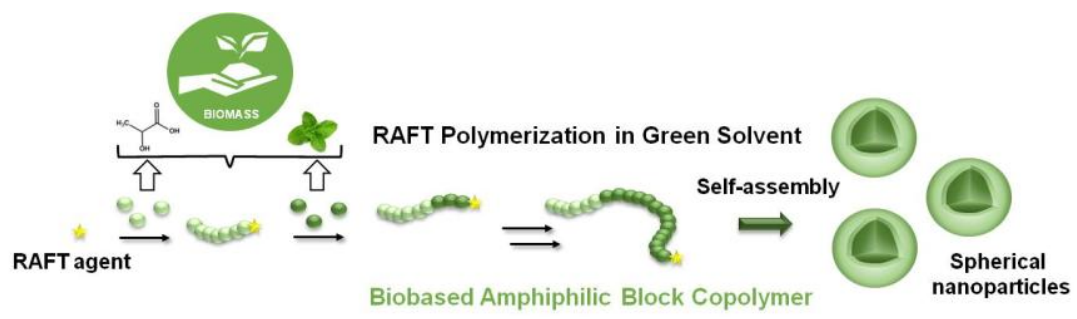

